\title{
Multivalued representation and new algebraic structures for fuzzy numbers
}

\section{DORINA FECHETE and IOAN FECHETE}

\section{ABSTRACT.}

In this paper we introduce a new representation of fuzzy numbers (called the multivalued representation) and a new multiplication on the set $\mathfrak{F}$ of fuzzy numbers. Introducing a Dorroh type product between fuzzy numbers, we construct some semiring structures on the set $\mathfrak{F}$. Two important particular cases of the general Dorroh type product are the cross product, introduced in [Ban, A. I. and Bede, B., Properties of the cross product of fuzzy numbers, Journal of Fuzzy Mathematics, 14 (2006), 513-531] and the Dorroh product, introduced in this paper. An equivalence relation, compatible with the addition and the Dorroh product, is also given.

\section{REFERENCES}

[1] Ban, A. I. and Bede, B., Properties of the cross product of fuzzy numbers, Journal of Fuzzy Mathematics, 14 (2006), 513-531

[2] Ban, A. I. and Bica, A., Solving systems of equivalentions, J. Applied Math. \& Computing, 20 (2006), No. (1-2), 97-118

[3] Bede, B., Mathematics of Fuzzy Sets and Fuzzy Logic, Springer-Verlag Berlin Heidelberg, 2013

[4] Bede, B. and Fodor, J., Product type operations between fuzzy numbers and their applications in geology, Acta Polytechnica Hungarica, 3 (2006) 123-139

[5] Bica, A. M., One-sided fuzzy numbers and applications to integral equations from epidemiology, Fuzzy Sets Syst., 219 (2013) 27-48

[6] Bica, A. M., Algebraic structures for fuzzy numbers from categorial point of view, Soft Computing, 11 (2007) 1099-1105

[7] Bouchon-Meunier, B., Kosheleva, O., Kreinovich, V. and Nguyen, H. T., Fuzzy numbers are the only fuzzy sets that keep invertible operations invertible, Fuzzy Sets Syst., 91 (1997), 155-163

[8] Demirci, M., Products of elements in vague semigroups and their implementations in vague arithmetic, Fuzzy Sets Syst., 156 (2005), 93-123

[9] Di Lascio, L. and Gisolfi, A., On the algebraic properties of some fuzzy numbers, J Fuzzy Math, 10 (2002), No. 1, $151-168$

[10] Dorroh, J. L., Concerning adjunctions to algebras, Bull. Amer. Math. Soc., 38 (1932), 85-88

[11] Dorsey, T. J. and Mesyan, Z., On minimal extensions of rings, Comm. Algebra, 37 (2009), 3463-3486

[12] Dubois, D. and Prade, H., Operations on fuzzy numbers, Int. J. Syst. Sci., 9 (1978), 613-626

[13] Dubois, D., and Prade, H., Fuzzy sets and systems: theory and applications, Academic Press, New York, 1980

[14] Fechete, D., Some categorial aspects of the Dorroh extensions, Acta Polytechnica Hungarica, 8 (2011), No. 4, $149-160$

[15] Filev, D. P. and Yager, R. R., Operations on fuzzy numbers via fuzzy reasoning, Fuzzy Sets Syst., 91 (1997), $137-142$

[16] Froda, A., Sur la distribution des proprietes de voisinage des functions de variables reelles, These, Harmann, Paris, 3 December 1929

[17] Giachetti, R. E. and Young, R. E., A parametric representation of fuzzy numbers and their arithmetic operators, Fuzzy Sets Syst., 91 (1997), 185-202

[18] Goetschel, R. and Voxman, W., Elementary fuzzy calculus, Fuzzy Sets Syst., 18 (1986), 31-43

Received: 05.04.2013; In revised form: 15.07.2013; Accepted: 15.01.2014

2010 Mathematics Subject Classification. 03E72, 08A72, 16Y60.

Key words and phrases. Fuzzy number, semiring, semimodule, Dorroh extension, trivial extension.

Corresponding author: Ioan Fechete; ifechete@uoradea.ro 
[19] Golan, J. S., Semirings and their Applications, Kluwer Academic Publishers, Dordrecht, 1999

[20] Hanss, M., Applied Fuzzy Arithmetic - An Introduction with Engineering Applications, Springer-Verlag, Berlin, 2005

[21] Klir, G. J., Fuzzy arithmetic with requisite constraints, Fuzzy Sets Syst., 91 (1997), 165-175

[22] Ma, M., On embedding problems of fuzzy number spaces: Part 4, Fuzzy Sets Syst., 58 (1993) 185-193

[23] Ma, M., Friedman, M. and Kandel, A., A new fuzzy arithmetic, Fuzzy Sets Syst., 108 (1999), 83-90

[24] Mareš, M., Weak arithmetics of fuzzy numbers, Fuzzy Sets Syst., 91 (1997), 143-153

[25] Mendel, J. M., Uncertain Rule-Based Fuzzy Logic Systems: Introduction and New Directions, Prentice-Hall, Upper-Saddle River, NJ, 2001

[26] Mesyan, Z., The ideals of an ideal extension, J. Algebra Appl., 9 (2010), 407-431

[27] Rudin, W., Principles of Mathematical Analysis, McGraw-Hill, 1964

[28] Stefanini, L., Sorini, L. and Guerra, M. L., Parametric representation of fuzzy numbers and applications to fuzzy calculus, Fuzzy Sets Syst., 157 (2006), 2423-2455

[29] Wu, C., and Gong, Z., On Henstock integral of fuzzy-number-valued functions (I), Fuzzy Sets Syst., 120 (2001), 523-532, 2009, pp. 281-304

\section{DEPARTMENT OF MATHEMATICS AND INFORMATICS}

UNIVERSITY OF ORADEA

UNIVERSITĂŢII 1, 410087, ORADEA, ROMANIA

E-mail address: dfechete@uoradea.ro

E-mail address: ifecheteduoradea.ro 